\title{
Article \\ NVCL-Based Galacto-Functionalized and Thermosensitive Nanogels with GNRDs for Chemo/Photothermal-Therapy
}

\author{
Mirian A. González-Ayón ${ }^{1, *}$, Jacob Licea-Rodriguez ${ }^{2,3}$ () Eugenio R. Méndez ${ }^{2}$ (†) and Angel Licea-Claverie ${ }^{1, *}$ \\ 1 Centro de Graduados e Investigación en Química, Tecnológico Nacional de México/Instituto Tecnológico de \\ Tijuana, Apartado Postal 1166, Tijuana 22454, Mexico \\ 2 División de Física Aplicada, Centro de Investigación Científica y Educación Superior de Ensenada, \\ Carretera Ensenada-Tijuana No. 3918, Ensenada 22860, B. C., Mexico; jlicea@cicese.mx (J.L.-R.); \\ emendez@cicese.edu.mx (E.R.M.) \\ 3 Cátedras CONACYT-Centro de Investigación Científica y Educación Superior de Ensenada, \\ Ensenada 22860, B. C., Mexico \\ * Correspondence: mirian.gonzalez@tectijuana.edu.mx (M.A.G.-A.); aliceac@tectijuana.mx (A.L.-C.)
}

check for updates

Citation: González-Ayón, M.A.; Licea-Rodriguez, J.; Méndez, E.R.; Licea-Claverie, A. NVCL-Based Galacto-Functionalized and Thermosensitive Nanogels with GNRDs for Chemo/Photothermal -Therapy. Pharmaceutics 2022, 14, 560. https://doi.org/10.3390/ pharmaceutics 14030560 Academic Editor: Franco Dosio

Received: 27 January 2022 Accepted: 25 February 2022 Published: 3 March 2022

Publisher's Note: MDPI stays neutral with regard to jurisdictional claims in published maps and institutional affiliations.

Copyright: (C) 2022 by the authors. Licensee MDPI, Basel, Switzerland. This article is an open access article distributed under the terms and conditions of the Creative Commons Attribution (CC BY) license (https:// creativecommons.org/licenses/by/ $4.0 /)$.

\begin{abstract}
Dual-function nanogels (particle size from 98 to $224 \mathrm{~nm}$ ) synthesized via surfactant-free emulsion polymerization (SFEP) were tested as smart carriers toward synergistic chemo- and photothermal therapy. Cisplatin (CDDP) or doxorubicin (DOX) and gold nanorods (GNRDs) were loaded into galacto-functionalized PNVCL-based nanogels, where the encapsulation efficiency for CDDP and DOX was around 64 and 52\%, respectively. PNVCL-based nanogels were proven to be an efficient delivery vehicle under conditions that mimic the tumor site in vitro. The release of CDDP or DOX was slower at $\mathrm{pH} 7.4$ and $37^{\circ} \mathrm{C}$ than at tumor conditions of $\mathrm{pH} 6$ and $40^{\circ} \mathrm{C}$. On the other hand, in the systems with GNRDs at $\mathrm{pH} 7.4$ and $37^{\circ} \mathrm{C}$, the sample was irradiated with a $785 \mathrm{~nm}$ laser for $10 \mathrm{~min}$ every hour, obtaining that the release profiles were even higher than in the conditions that simulated a cancer tissue (without irradiation). Thus, the present study demonstrates the synergistic effect of chemo- and photothermal therapy as a promising dual function in the potential future use of PNVCL nanogels loaded with GNRDs and CDDP/DOX to achieve an enhanced chemo/phototherapy in vivo.
\end{abstract}

Keywords: nanogels; gold nanorod; cisplatin; doxorubicin; chemo- and photothermal therapy

\section{Introduction}

Nanogels are cross-linked polymers of nanometric size in the form of a three-dimensional network that combine the advantages of nanotechnology with the hydrophilicity and flexibility of hydrogels. They are considered promising drug carriers due to their large surface area, porous structure, good biocompatibility, and relatively easy functionalization of their surface. Additionally, when they can respond to internal or external stimuli by changing their structural characteristics and hydrophilic-hydrophobic balance, they are classified as smart nanogels [1].

Currently, different nanogels with tailored properties have been developed with potential applications in the treatment of cancer [2]. Some of them have been synthesized in response to stimuli such as temperature, $\mathrm{pH}$, or enzymes, mainly focused on passive targeting [3]; while others have been developed by modifying their surface with biological ligands, such as proteins, polysaccharides, peptides, and other small molecules, for both passive and active targeting through recognition of cancer cell receptors [4]. The potential application of these systems has been investigated in improving chemotherapy and radiotherapy. On the one hand, different anticancer drugs have been encapsulated with the aim of achieving site-specific chemotherapy [5]. In addition, they have also been studied as encapsulants of metallic nanoparticles, such as hollow gold nanoshells, gold nanorods (GNRDs), quantum dots, carbon nanotubes, and graphene nanosheets to induce localized 
hyperthermia in cancer therapy [6-11]. Specifically, GNRDs show structure-dependent optical properties, with a tunable photothermal response to light [12], typically showing two absorption bands in the UV-vis spectrum, one transversal at $520 \mathrm{~nm}$, while the other longitudinal can be tuned within the visible or near-infrared (NIR) spectrum. According to the literature, with a single treatment of only chemotherapy or photothermal therapy, it is difficult to completely eradicate tumor cells due to the lack of drug targeting and the uneven distribution of heat at the tumor site. Therefore, in order to completely eradicate tumor cells, chemotherapy and photothermal therapy have been combined. Recently, some studies have shown that the combination of these strategies using GNRDs has resulted in synergistic anticancer efficacy from in vitro and in vivo models [13]. In addition, it has been recently shown that gold nanoparticles are not only physical dose enhancers (ionization) but also cause chemical and biological impacts on cells. The physical effect occurs by the generation of photoelectrons and Auger electrons, while the chemical/biological effects include oxidative stress and reactive oxygen species production, DNA damage and reduced repair, cell cycle arrest, and bystander effects. These synergistic effects highlight the great importance of targeting GNRDs in cancer treatment [14,15].

Among stimulus-sensitive drug carriers, heat-sensitive polymers, such as poly $(\mathrm{N}$ vinylcaprolactam) (PNVCL), induce a phase transition of its cross-linked polymer in water with increasing temperature above a critical value $\left(\mathrm{T}_{\mathrm{VPT}}\right)$. This thermo-responsiveness plays a key role, given that it can be adjusted to the human body temperature by copolymerization with hydrophilic comonomers, such as poly(ethylene glycol) (PEG), which allows having control over drug release based on temperature changes in the body. Furthermore, PNVCL is a biocompatible polymer, and the possible hydrolysis of the amide group of the NVCL may produce a polymeric carboxylic acid, which is innocuous for biomedical applications $[16,17]$. Therefore, these smart materials offer new promising perspectives for the development of next-generation therapeutic agents [17]. According to previous reports, nanogels from poly(NVCL-VP-PEGMA) and poly(NVCL-2MBA-PEGMA) [18], fibrinogen-graft-poly(N-vinylcaprolactam) [19], poly(NVCL-co-methacrylic acid)-PEG [20], PNVCL-poly(acrylamidoglycolic acid) [21], and poly(6-O-vinyladipoyl-D-galactose-ss- $\mathrm{N}$ vinylcaprolactam-ss-methacrylic acid) [22], have potential as pharmaceutical carriers of the well-known chemotherapeutic agents 5-fluoruracyl (5FU) or doxorubicin (DOX).

Previously, we developed two families of temperature-sensitive PNVCL-based nanogels via surfactant-free emulsion polymerization (SFEP) (Scheme 1). The first one, with tailored transition temperature (PNVCL:VP:PEGMA) [18], and the second one galacto-functionalized nanogels (PNVCL:GAL:PEGMA) [23], towards their potential use in the transport of anticancer drugs to target cancer cells, which could be driven by Galectin3-galactan affinity. In the present communication, we report the application of PNVCL-based nanogels as a dual-function system by loading a chemotherapeutic agent like cisplatin (CDDP) or DOX and a photothermal agent (GNRDs), as described below. The GNRDs encapsulated in the nanogels provide sensitivity to light [24] or electromagnetic radiation [25,26]. Small GNRDs can be heated via light or radiofrequency radiation. Irradiation with NIR light of the GNRDs on the PNVCL-based nanogels is expected to cause the nanogel to shrink, even when the GNRDs are bound to the surface of the nanogels [27]. CDDP and DOX were tested since those agents are widely used in chemotherapy while being very different: one organic molecule (DOX) and one metal-based inorganic compound. Additionally, the galactose linking onto the nanogels can provide the target-specific property by improving the interaction between the nanoparticles and specific receptors of tumor cells [28,29]. In this investigation, two types of experiments were carried out: first, CDDP or DOX were loaded into selected nanogels, and then in vitro release was evaluated under conditions that mimic a healthy ( $\mathrm{pH} 7.4$ and $37^{\circ} \mathrm{C}$ ) and cancerous ( $\mathrm{pH} 6$ and $\left.40^{\circ} \mathrm{C}\right)$ tissue. Subsequently, GNRDs were encapsulated in nanogels with CDDP or DOX, and the release of the drug was evaluated at $\mathrm{pH} 7.4$ and $37^{\circ} \mathrm{C}$ irradiated with a $785 \mathrm{~nm}$ laser for $10 \mathrm{~min}$, every hour. These smart biomaterials are intended to improve cancer therapy, overcoming some drawbacks of conventional treatments. 


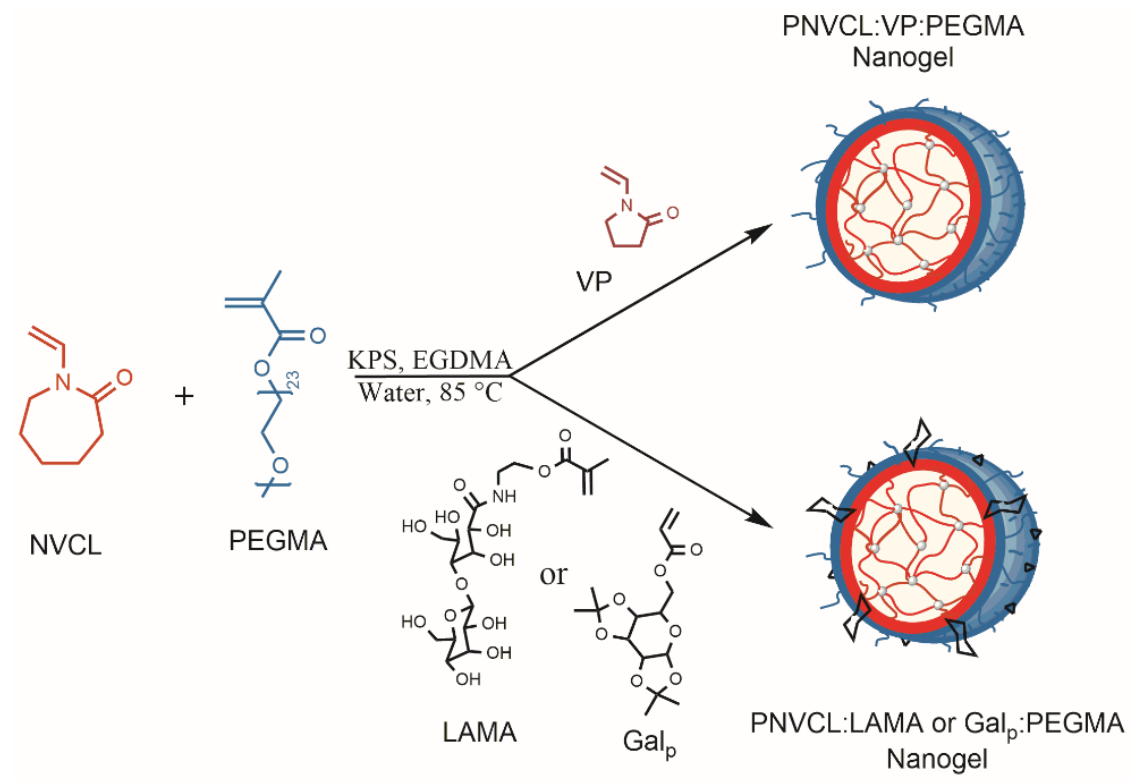

Scheme 1. Core-shell nanogels synthesized by SFEP for encapsulation CDDP or DOX and GNRDs.

\section{Materials and Methods}

\subsection{Materials}

N-Vinylcaprolactam (NVCL, 98\%) was purified by recrystallization in hexane and dried under vacuum prior to use. Poly(ethylene glycol) methyl ether methacrylate (PEGMA, $\mathrm{M}_{\mathrm{n}}=950 \mathrm{gmol}^{-1}$ ), and ethylene glycol dimethacrylate (EGDMA, 98\%), were purified by filtering through an inhibitor remover column. The GAL monomer 2-lactobionamidoethyl methacrylate (LAMA) was synthesized following a procedure reported previously [23], while another commercially available GAL monomer was also used: 6-O-acryloyl-1,2,3,4bis-O-(1-methyl-ethylidene)- $\alpha$-D-galactopiranose $\left(\mathrm{Gal}_{\mathrm{p}}\right) . N$-vinylpyrrolidone (VP, 99\%), potassium persulfate (KPS, 98\%), cis-diammine-platinum (II) dichloride (CDDP), doxorubicin hydrochloride (DOX), cetyltrimethylammonium bromide (CTAB, 99\%), gold (III) chloride hydrate, sodium borohydride $\left(\mathrm{NaBH}_{4}, 99 \%\right)$, silver nitrate $\left(\mathrm{AgNO}_{3}, 99 \%\right)$, sulfuric acid $\left(\mathrm{H}_{2} \mathrm{SO}_{4}, 98 \%\right)$, and ascorbic acid (AA, 98\%), were used as received. Deuterated and non-deuterated solvents and all reagents were purchased from Sigma-Aldrich (Toluca, Mexico); with one exception, commercial-grade distilled water (Sparkletts, Lakeside, CA, USA).

\subsection{Preparation of NVCL-Based Nanogels}

Nanogels were obtained by surfactant-free emulsion polymerization (SFEP) via a free radical mechanism, in accordance with previous reports $[18,23]$. In a typical experiment, the reaction mixture containing NVCL, PEGMA, EGDMA, and GAL-monomer in water, was added to a Schlenk flask containing a magnetic stir-bar and connected to a nitrogen inlet. The mixture was placed in a preheated oil bath at $85{ }^{\circ} \mathrm{C}$, and after $20 \mathrm{~min}$ the thermal initiator, KPS, was added to the reaction system for starting the polymerization. The reaction was stopped after $30 \mathrm{~min}$ by cooling. Finally, the products were purified by dialysis (dialysis membrane Spectra/Por ${ }^{\circledR}, \mathrm{MWCO}=12-14 \mathrm{kDa}$ ) against deionized water for 5 days. Samples were frozen and lyophilized on a Labconco Freeze Dry System Freezone 4.5 (Kansas City, MI, USA). Then, the products were stored in a refrigerator until use. Particle size was determined by dynamic light scattering (DLS) using a Malvern Instruments Zetasizer Nano-ZS (ZEN 3690) (Malvern-Panalytical, Malvern, Worcestershire, UK) equipped with a red laser $(630 \mathrm{~nm})$ and a measurement detector at $90^{\circ}$. Using the same equipment, the response temperature $\left(\mathrm{T}_{\mathrm{VPT}}\right)$ of the nanogels was analyzed by DLS. The effect of temperature on the particle size was studied using dispersions at $1 \mathrm{mg} \mathrm{mL}^{-1}$ of nanogels in water, while the temperature was varied from 20 to $50{ }^{\circ} \mathrm{C}$ with 4 min of 
equilibration time between each temperature value. The reported $\mathrm{T}_{\mathrm{VPT}}$ was taken as the minimum of the derivative of $\mathrm{dD}_{\mathrm{h}} / \mathrm{dT}$.

\subsection{Loading of Drugs into Nanogels}

CDDP and DOX were used as model anticancer drugs to evaluate the loading and release capacity of nanogels, using the equilibrium swelling method. For the encapsulation of CDDP or DOX, the first $10 \mathrm{mg}$ of the drug were dispersed in $5 \mathrm{~mL}$ of deionized water, and then $20 \mathrm{mg}$ of dry nanogels were dispersed in this solution, and the mixture was stirred for $24 \mathrm{~h}$. Afterward, the drug-loaded nanogels were dialyzed against water for $4 \mathrm{~h}$ to remove surface adsorbed and non-encapsulated drug, using a membrane Spectra/Por ${ }^{\circledR}$, MWCO: $12-14 \mathrm{kDa}$. The loaded nanogels were frozen at $-4{ }^{\circ} \mathrm{C}$ in a conventional freezer for $12 \mathrm{~h}$ and then placed into the drying chamber of a Labconco Freeze Dry System Freezone 4.5 (Kansas City, MO, USA), precooled to $-50{ }^{\circ} \mathrm{C}$; drying was performed at 0.05 mbar for $24 \mathrm{~h}$. The drug-loaded nanogels were dispersed in a PBS buffer at pH 6 or pH 7.4 and assayed spectroscopically using an ICP (Inductively Coupled Plasma) for CDDP content; while for DOX content, a UV-vis Cary 100 Spectrophotometer (Varian) at $480 \mathrm{~nm}$ was employed. The drug loading (\%DL) and encapsulation efficiency (\%EE) were calculated using Equations (1) and (2), respectively [20]:

$$
\begin{aligned}
& \% \mathrm{DL}=\left(\frac{\text { MDng }}{\text { mass of nanogels }+ \text { MDng }}\right) \times 100 \\
& \% \mathrm{EE}=\left(\frac{\text { initial MD }- \text { MD supernant }}{\text { initial MD }}\right) \times 100
\end{aligned}
$$

where MD is the mass of drug and MDng is the mass of drug in the nanogel.

\subsection{Loading of GNRDs into Nanogels}

Gold nanorods (GNRDs) were synthesized in an aqueous CTAB solution using a seed growth method [30]. Briefly, gold seeds were prepared by adding $\mathrm{HAuCl}_{4}(10 \mathrm{mM}$, $0.25 \mathrm{~mL})$, to CTAB $(0.1 \mathrm{M}, 7.5 \mathrm{~mL})$, then $\mathrm{NaBH}_{4}(10 \mathrm{mM}, 600 \mu \mathrm{L})$ was added under stirring. Growth solution was prepared by adding $\mathrm{HAuCl}_{4}(10 \mathrm{mM}, 5 \mathrm{~mL})$ to CTAB $(0.1 \mathrm{M}, 100 \mathrm{~mL})$ solution, and then $\mathrm{AgNO}_{3}(10 \mathrm{mM}, 1 \mathrm{~mL})$ and ascorbic acid $(100 \mathrm{mM}, 0.8 \mathrm{~mL})$ were added. Next, the seed solution $(7.5 \mathrm{~mL})$ was added to a growth solution $(0.25 \mathrm{~mL})$. Centrifugation $(11,000 \mathrm{rpm}$ for $10 \mathrm{~min}$ ) was used for purification. GNRDs were characterized by transition electron microscopy (TEM) and UV-vis spectroscopy according to procedures previously reported [30].

To load GNRDs into the nanogel, a GNRD solution $(50 \mu \mathrm{g} / 100 \mu \mathrm{L}$ deionized water) was added into a powdery state of nanogel $(3 \mathrm{mg})$ using a vortex; this was followed by incubation at room temperature for $12 \mathrm{~h}$, and then incubation at $4{ }^{\circ} \mathrm{C}$ for $12 \mathrm{~h}$. The mixture solution remained motionless at room temperature for $24 \mathrm{~h}$. Next, the liquid part, which contained the stabilized GNRDs in the nanogels, was carefully separated from the unstable GNRDs that precipitated in the container. The precipitate was placed in a pre-weighed vial that was subsequently placed in a vacuum oven at $40{ }^{\circ} \mathrm{C}$ for $48 \mathrm{~h}$ to dry completely and then reweighed. The percentage of GNRDs loaded was evaluated by weight difference between the original amount of GNRDs added to the solution and the weight of the precipitated GNRDs. The data obtained in percentage are shown in Table S2 (Supplementary Information file). The liquid part, GNRDs loaded in nanogels, were then frozen and lyophilized in a Labconco Freeze Dry System Freezone 4.5 (Kansas City, MO, USA). Then, the GNRD-loaded nanogels were stored in a freezer until use.

\subsection{In Vitro Drug Release Profile of CDDP/DOX}

In vitro release studies were performed under sink conditions at controlled temperature and agitation. Two operating conditions were established. On the one hand, $37^{\circ} \mathrm{C}$ and $\mathrm{pH} 7.4$ were selected as conditions that mimic the environment of a healthy body, 
and on the other hand, $40^{\circ} \mathrm{C}$ and $\mathrm{pH} 6$ were selected as conditions that mimic the tumor microenvironment. In both cases, constant stirring was maintained at $90 \mathrm{rpm}$. Typically, $5 \mathrm{mg}$ of drug-loaded nanogels were dispersed in $3 \mathrm{~mL}$ of the corresponding buffer and then placed in a dialysis bag, which was subsequently immersed in $300 \mathrm{~mL}$ of the release medium at the desired temperature. At predetermined time intervals, an aliquot $(3 \mathrm{~mL})$ was withdrawn, and $3 \mathrm{~mL}$ of clean PBS was added to keep the volume of the release medium constant. The percentage of drug released (\%DR) was calculated by Equation (3) [18]:

$$
\% \mathrm{DR}=\left(\frac{\text { mass of drug released from nanogels }}{\text { mass of total drug loaded in nanogels }}\right) \times 100
$$

Similar to the quantification of the loaded drug into nanogels, the evaluation of the drug released from them was performed spectroscopically by ICP (inductively coupled plasma) for CDDP and by UV-vis spectrophotometry for DOX.

\section{Results}

\subsection{Preparation of PNVCL-Based Nanogels}

The synthesis of thermoresponsive PNVCL-based nanogels was carried out via PEGMAmediated SFEP. This method allows the preparation of core-shell nanogels with controlled size and responsive behavior, as previously reported. In this contribution, two families of nanogels were used: PNVCL:PEGMA nanogels with VP, synthesis described in [18] for tuning the transition temperature (samples NG1 to NG3 in Table 1), and PNVCL:PEGMA nanogels with galactose (GAL), described in [23] to target cancer cells (samples NG4 to NG6 in Table 1). In the case of nanogels with galactose, $\mathrm{Gal}_{\mathrm{p}}$ or LAMA were used. As determined gravimetrically, conversions were between 50 and $60 \mathrm{wt} \%$ (Table 1). Colloidal stable particles were characterized by means of DLS, ${ }^{1} \mathrm{H}-\mathrm{NMR}, \mathrm{DSC}$, and other methods (see Table S1 and Figures S1-S10 in Supplementary Information File). The nomenclature used according to the molar composition is the following: PNVCL92:PEGMA 8 (NG1), $\mathrm{PNVCL}_{60}: \mathrm{VP}_{21}: \mathrm{PEGMA}_{19}$ (NG2), PNVCL $53: \mathrm{VP}_{26}: \mathrm{PEGMA}_{21}$ (NG3), PNVCL 60 :GAL 23 : PEGMA $_{17}$ (NG4), PNVCL 68 :LAMA 6 :PEGMA 26 (NG5), and PNVCL 81 :VP $:$ LAMA $_{3}:$ PEGMA $_{8}$ (NG6). The size for all nanogels was obtained by DLS (Figure 1).

Table 1. Composition of nanogels, transition temperature, and yield.

\begin{tabular}{|c|c|c|c|c|c|c|c|c|}
\hline \multirow{2}{*}{ Nanogel } & \multicolumn{4}{|c|}{ Product Composition (mol\%) ${ }^{a}$} & \multicolumn{3}{|c|}{$\mathbf{T}_{\mathrm{VPT}}\left({ }^{\circ} \mathrm{C}\right)^{\mathrm{b}}$} & \multirow[t]{2}{*}{$\begin{array}{c}\text { Yield } \\
(w t \%)\end{array}$} \\
\hline & NVCL & PEGMA & GAL & VP & Water & pH 7.4 & pH 6 & \\
\hline NG1 & 92 & 8 & 0 & 0 & 28 & 29 & 29 & 50 \\
\hline NG2 & 60 & 19 & 0 & 21 & 34 & 34 & 32 & 55 \\
\hline NG3 & 53 & 21 & 0 & 26 & 42 & 40 & 40 & 53 \\
\hline NG4 & 60 & 17 & $\mathrm{Gal}_{\mathrm{p}} 23$ & 0 & 41 & 39 & 39 & 62 \\
\hline NG5 & 68 & 26 & LAMA6 & 0 & 32 & 32 & 31 & 60 \\
\hline NG6 & 81 & 8 & LAMA3 & 8 & 37.5 & 35 & 37 & 58 \\
\hline
\end{tabular}

a As determined by ${ }^{1} \mathrm{H}-\mathrm{NMR} ;{ }^{\mathrm{b}}$ as determined by DLS.

\subsection{Drug Loading and In Vitro Release Study}

The drug loading and release from nanogels depends on factors related to the polymer network (composition, structure, and size), the guest molecule (chemical structure and molecular weight), the possible chemical interactions that occur between both, and the release conditions (temperature, $\mathrm{pH}$ ). In the case of CDDP and DOX, they are DNA inhibitor drugs widely used in chemotherapy [31,32], which have been encapsulated in nanogels and microgels $[33,34]$. In order to overcome the disadvantages of conventional administration of these drugs, the potential of nanogels based on PNVCL:VP:PEGMA and PNVCL:GAL:PEGMA for encapsulation and release of CDDP or DOX was tested in our study. Figure 2 shows the drug loading and encapsulation efficiency of CDDP (Figure 2a) or 
DOX (Figure 2b) into nanogels. For galacto-functionalized nanoparticles, the encapsulation efficiency for CDDP and DOX was, on average, 64 and 53\%, respectively.

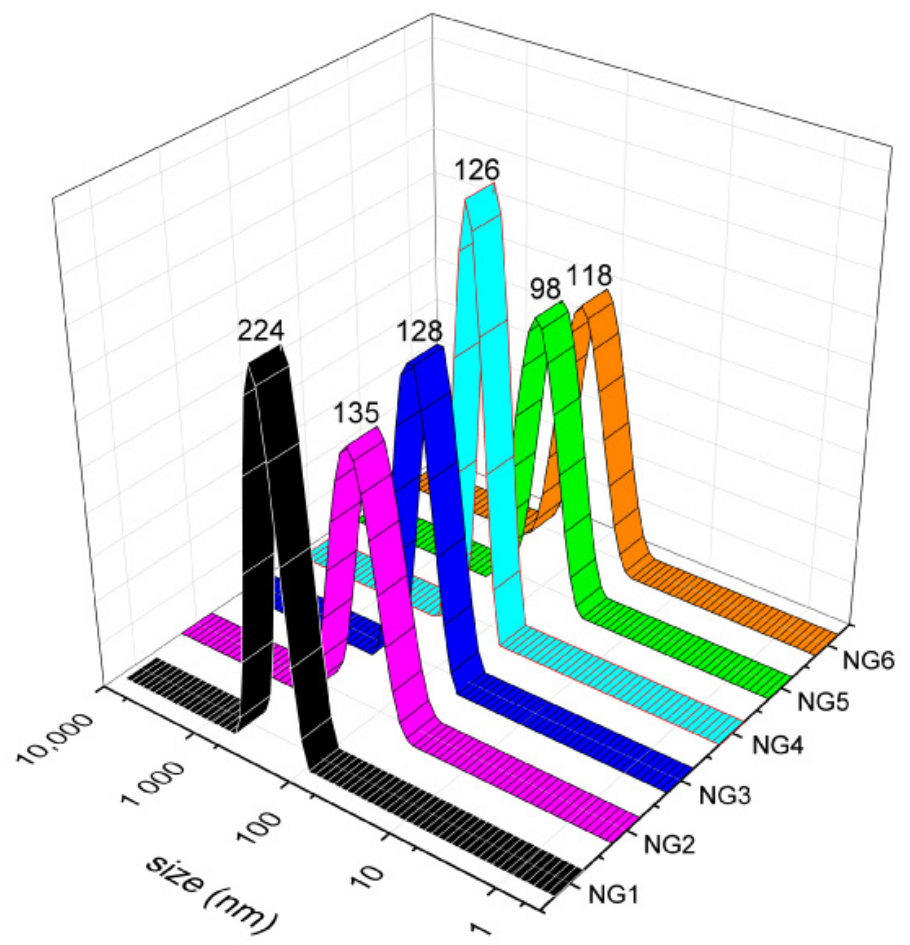

Figure 1. Size distribution by intensity of PNVCL-based nanogels containing VP or GAL.

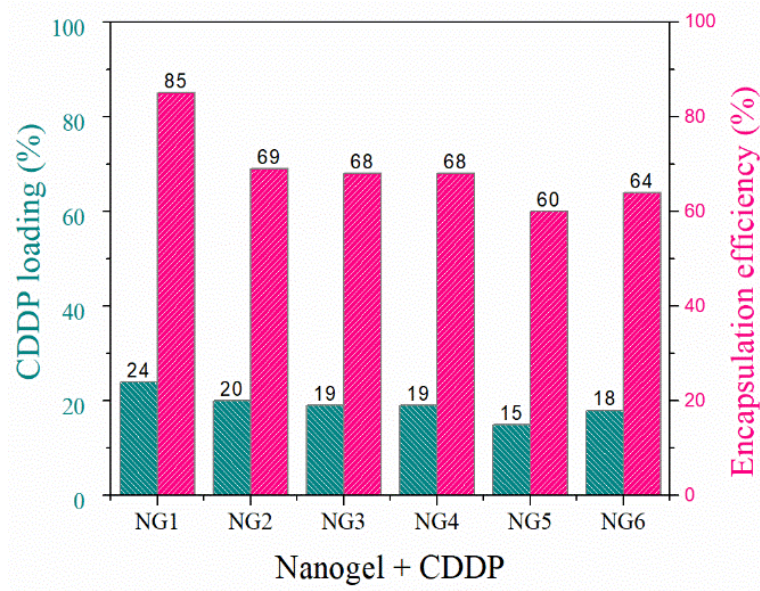

(a)

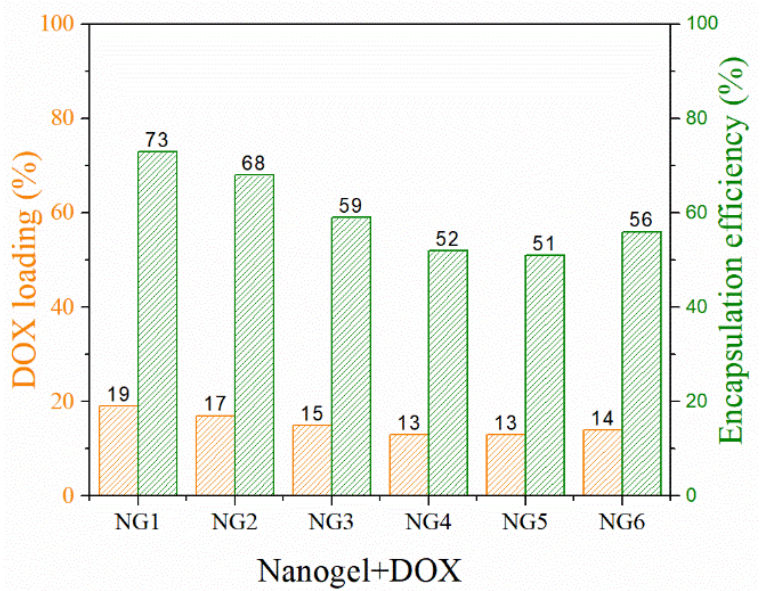

(b)

Figure 2. Drug loading and encapsulation efficiency of drugs in nanogels: (a) CDDP, (b) DOX.

According to previous studies, the normal $\mathrm{pH}$ of blood for sustaining human life is around 7.4, while tumor tissue has a lower extracellular $\mathrm{pH}$, between 6.5 and 7.2, and drops to a $\mathrm{pH}$ from 5 to 5.5 when reaching the endosomes and lysosomes [35]. Therefore, in vitro drug release studies were carried out mimicking physiological conditions of healthy ( $\mathrm{pH} 7.4$ and $37^{\circ} \mathrm{C}$ ) and cancer ( $\mathrm{pH} 6$ and $40{ }^{\circ} \mathrm{C}$ ) tissues. The $\mathrm{pH}$ was adjusted using $0.1 \mathrm{mM}$ phosphate buffers. The nanogels were divided into two families: nanogels with a tailored transition temperature (PNVCL:VP:PEGMA) and galacto-functionalized nanogels (PNVCL:GAL:PEGMA). Figure 3a-d shows the cumulative release profiles for CDDP from these nanogels (NG1 to NG6), while Figure 4a,b display the release profiles of DOX using selected nanogels (NG3 to NG6). From these trials, it was demonstrated that there is a 
marked effect of temperature and $\mathrm{pH}$ on the cumulative drug release for the designed systems.

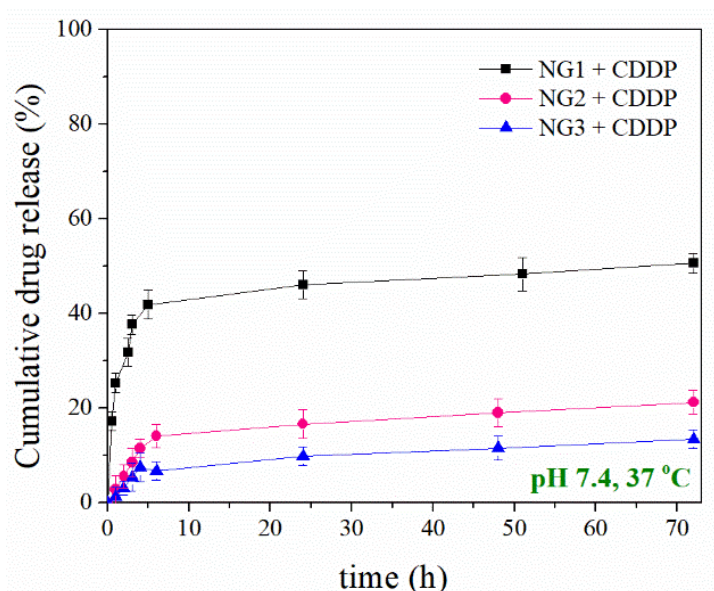

(a)

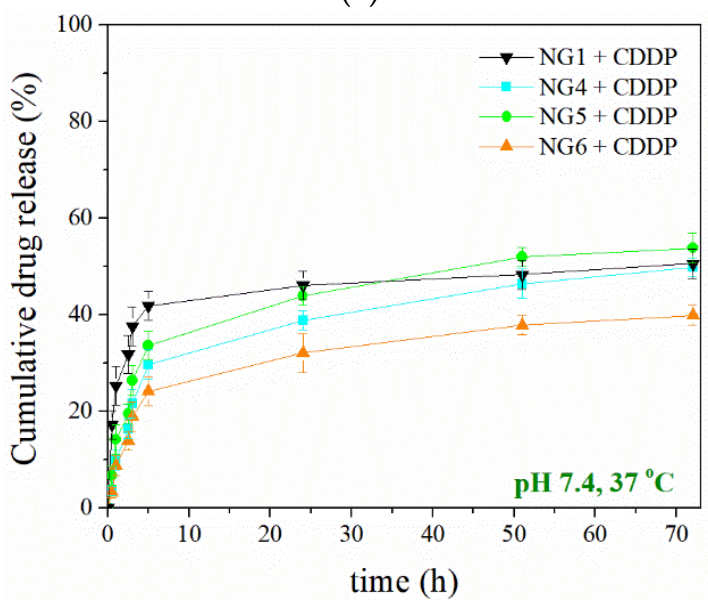

(c)

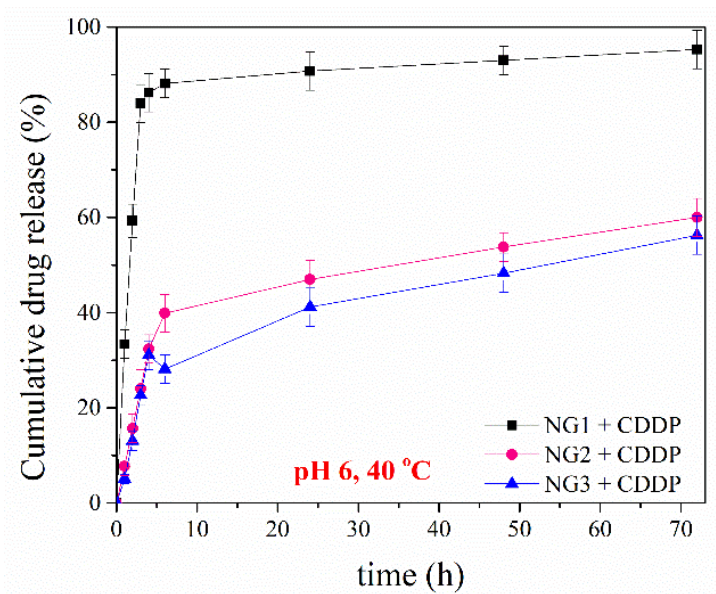

(b)

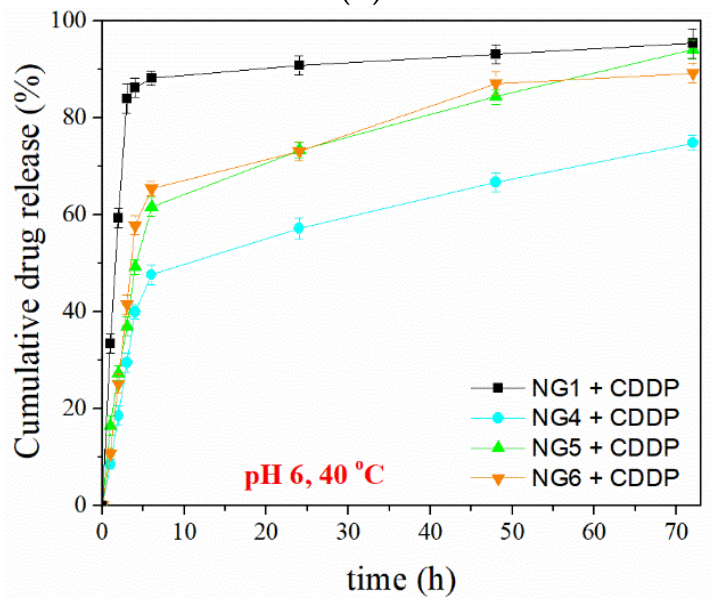

(d)

Figure 3. Cumulative CDDP release from nanogels at different conditions. From PNVCL:VP:PEGMA nanogels: (a) at $\mathrm{pH} 7.4, \mathrm{~T}=37^{\circ} \mathrm{C}$; (b) at $\mathrm{pH} 6, \mathrm{~T}=40^{\circ} \mathrm{C}$. From PNVCL:GAL:PEGMA nanogels: (c) at $\mathrm{pH} 7.4, \mathrm{~T}=37^{\circ} \mathrm{C} ;(\mathbf{d})$ at $\mathrm{pH} 6, \mathrm{~T}=40^{\circ} \mathrm{C}$.

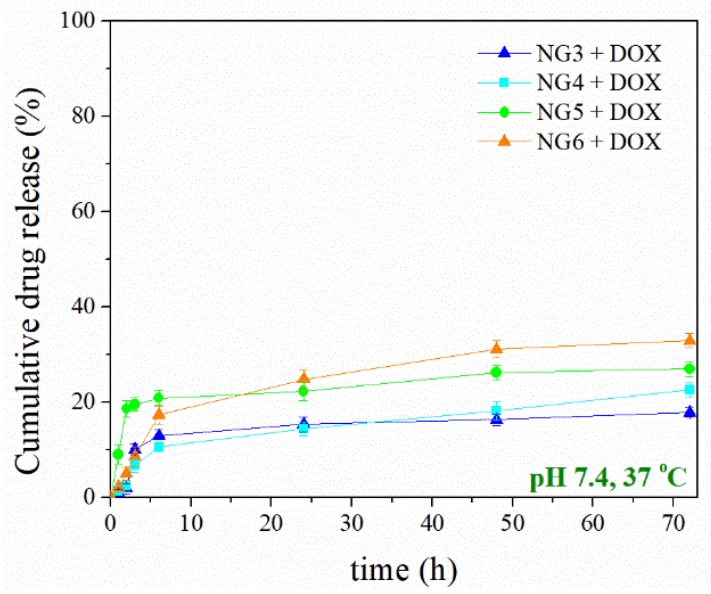

(a)

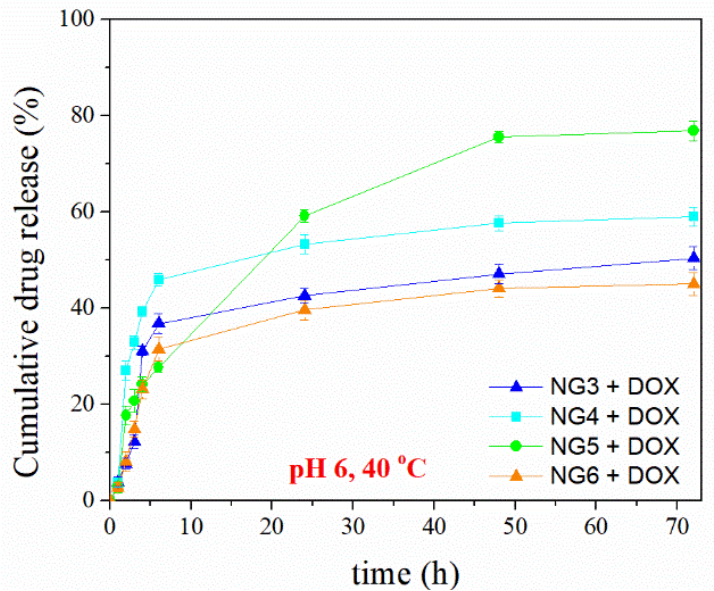

(b)

Figure 4. Cumulative DOX release from PNVCL:VP:PEGMA and PNVCL:GAL:PEGMA nanogels at (a) $\mathrm{pH} 7.4, \mathrm{~T}=37^{\circ} \mathrm{C}$ and at (b) $\mathrm{pH} 6, \mathrm{~T}=40^{\circ} \mathrm{C}$. 
Mathematical models were applied to evaluate the kinetics of CDDP (Table 2) and DOX (Table 3) release from nanogels. Data were fitted by Equations (4)-(6) using a linear and no linear regression analysis [36].

$$
\begin{gathered}
\text { First order : } F=1-e^{-k t} \\
\text { Higuchi equation : } F=k t^{0.5} \\
\text { Peppas equation : } F=k t^{n}
\end{gathered}
$$

where: $F$ is fractional drug release, $k$ is release rate constant for the different equations, $n$ is the diffusional exponent.

Table 2. Release rate for CDDP: in vitro release data fitted with different models.

\begin{tabular}{ccccc}
\hline Nanogel & $\begin{array}{c}\text { Conditions for } \\
\text { Release }\end{array}$ & $\begin{array}{c}\text { First Order } \\
\left(\boldsymbol{k} ; \boldsymbol{r}^{\mathbf{2}} \mathbf{~} \mathbf{b}\right.\end{array}$ & $\begin{array}{c}\text { Higuchi } \\
\left(\boldsymbol{k} ; \boldsymbol{r}^{\mathbf{2}}\right)^{\mathbf{c}}\end{array}$ & $\begin{array}{c}\text { Peppas } \\
\left(\boldsymbol{k} ; \boldsymbol{n} ; \boldsymbol{r}^{\mathbf{2}} \mathbf{)}\right.\end{array}$ \\
\hline \multirow{2}{*}{ NG1 } & Healthy & $0.014 ; 0.99$ & $0.207 ; 0.98$ & $0.235 ; \mathbf{0 . 3 9} ; 0.97$ \\
& Cancer & $0.666 ; 0.98$ & $0.516 ; 0.98$ & $0.818 ; \mathbf{0 . 0 3} ; 0.99$ \\
\hline \multirow{2}{*}{ NG2 } & Healthy & $0.026 ; 0.98$ & $0.031 ; 0.99$ & $0.097 ; \mathbf{0 . 2 9} ; 0.99$ \\
& Cancer & $0.088 ; 0.99$ & $0.081 ; 0.99$ & $0.747 ; \mathbf{0 . 2 9} ; 0.99$ \\
\hline \multirow{2}{*}{ NG3 } & Healthy & $0.020 ; 0.99$ & $0.062 ; 0.99$ & $0.042 ; \mathbf{0 . 3 3} ; 0.99$ \\
& Cancer & $0.095 ; 0.98$ & $0.262 ; 0.99$ & $0.175 ; \mathbf{0 . 3 4} ; 0.99$ \\
\hline \multirow{2}{*}{ NG4 } & Healthy & $0.061 ; 0.99$ & $0.123 ; 0.90$ & $0.187 ; \mathbf{0 . 3 8} ; 0.98$ \\
& Cancer & $0.114 ; 0.98$ & $0.195 ; 0.93$ & $0.248 ; \mathbf{0 . 3 3} 0.98$ \\
\hline \multirow{2}{*}{ NG5 } & Healthy & $0.070 ; 0.99$ & $0.141 ; 0.94$ & $0.170 ; \mathbf{0 . 3 6} ; 0.98$ \\
& Cancer & $0.160 ; 0.99$ & $0.255 ; 0.97$ & $0.313 ; \mathbf{0 . 3 6} 0.99$ \\
\hline \multirow{2}{*}{ NG6 } & Healthy & $0.049 ; 0.99$ & $0.118 ; 0.93$ & $0.114 ; \mathbf{0 . 3 9} ; 0.98$ \\
& Cancer & $0.192 ; 0.97$ & $0.277 ; 0.95$ & $0.325 ; \mathbf{0 . 3 7} 0.97$ \\
\hline
\end{tabular}

a Mimic healthy $\left(\mathrm{pH} 7.4\right.$ and $37^{\circ} \mathrm{C}$ ) and cancer $\left(\mathrm{pH} 6\right.$ and $\left.40{ }^{\circ} \mathrm{C}\right)$ tissue conditions. ${ }^{\mathrm{b}}$ Obtained by Equation (4)

${ }^{c}$ Obtained by Equation (5). ${ }^{d}$ Obtained by Equation (6).

Table 3. Release rate for DOX: in vitro release data fitted with different models.

\begin{tabular}{ccccc}
\hline Nanogel & $\begin{array}{c}\text { Conditions for } \\
\text { Release }^{\mathbf{a}}\end{array}$ & $\begin{array}{c}\text { First Order } \\
\left(\boldsymbol{k} ; \boldsymbol{r}^{\mathbf{2}} \mathbf{b}\right.\end{array}$ & $\begin{array}{c}\text { Higuchi } \\
\left(\boldsymbol{k} ; \boldsymbol{r}^{\mathbf{2}} \mathbf{)}\right.\end{array}$ & $\begin{array}{c}\text { Peppas } \\
\left(\boldsymbol{k} ; \boldsymbol{n} ; \boldsymbol{r}^{\mathbf{2}} \mathbf{)}\right.\end{array}$ \\
\hline \multirow{2}{*}{ NG3 } & Healthy & $0.026 ; 0.86$ & $0.078 ; 0.99$ & $0.114 ; \mathbf{0 . 1 7} ; 0.98$ \\
& Cancer & $0.043 ; 0.99$ & $0.166 ; 0.91$ & $0.208 ; \mathbf{0 . 3 6} ; 0.98$ \\
\hline \multirow{2}{*}{ NG4 } & Healthy & $0.019 ; 0.96$ & $0.056 ; 0.88$ & $0.081 ; \mathbf{0 . 3 7} ; 0.93$ \\
& Cancer & $0.107 ; 0.92$ & $0.208 ; 0.98$ & $0.389 ; \mathbf{0 . 1 7} ; 0.94$ \\
\hline \multirow{2}{*}{ NG5 } & Healthy & $0.087 ; 0.91$ & $0.054 ; 0.87$ & $0.185 ; \mathbf{0 . 1 0} ; 0.99$ \\
& Cancer & $0.176 ; 0.92$ & $0.215 ; 0.88$ & $0.196 ; \mathbf{0 . 4 1} ; 0.90$ \\
\hline \multirow{2}{*}{ NG6 } & Healthy & $0.032 ; 0.99$ & $0.069 ; 0.86$ & $0.122 ; \mathbf{0 . 3 9} ; 0.99$ \\
& Cancer & $0.065 ; 0.98$ & $0.126 ; 0.83$ & $0.218 ; \mathbf{0 . 3 0} 0.99$ \\
\hline
\end{tabular}

a Mimic healthy $\left(\mathrm{pH} 7.4\right.$ and $37^{\circ} \mathrm{C}$ ) and cancer $\left(\mathrm{pH} 6\right.$ and $\left.40{ }^{\circ} \mathrm{C}\right)$ tissue conditions. ${ }^{\mathrm{b}}$ Obtained by Equation (4) ${ }^{\mathrm{c}}$ Obtained by Equation (5). ${ }^{\mathrm{d}}$ Obtained by Equation (6).

\subsection{GNRDs Encapsulation and Photothermal Studies}

Gold nanorods were synthesized by the seed growth method. The product was characterized by transition electron microscopy (Figure 5a) and UV-vis spectroscopy (Figure 5b). Subsequently, GNRDs and CDDP or DOX were encapsulated in selected nanogels from PNVCL:VP:PEGMA, PNVCL:GAL:PEGMA, and PNVCL:VP:GAL:PEGMA, checking the success of the encapsulation by UV-vis spectroscopy (Figure 6). Nanogels NG3 to NG6 were selected for dual encapsulation of GNRDs-drug because they are the ones that showed smaller size, higher transition temperature, and because of their LAMA content, in addition 
to their relatively low percentage of CDDP or DOX release in systems that mimic healthy tissue conditions (without GNRDs).

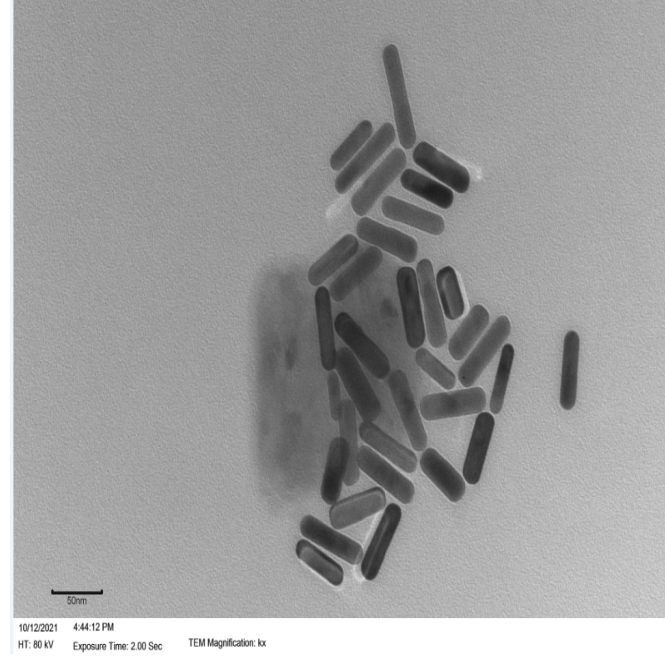

(a)

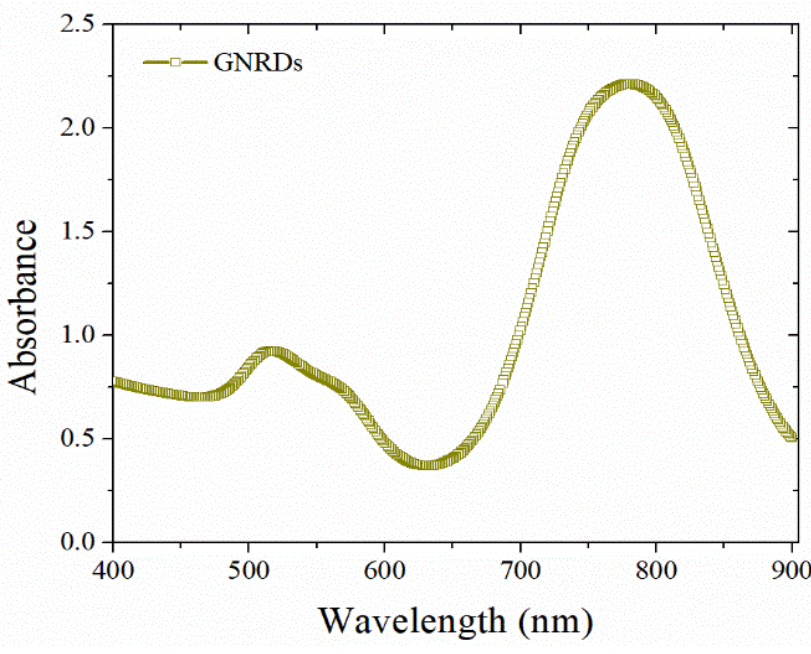

(b)

Figure 5. (a) TEM micrography of colloidal gold nanorods of aspect ratio of 3.75. (b) UV-vis spectrum showing the localized surface plasmon resonance of gold nanorods.

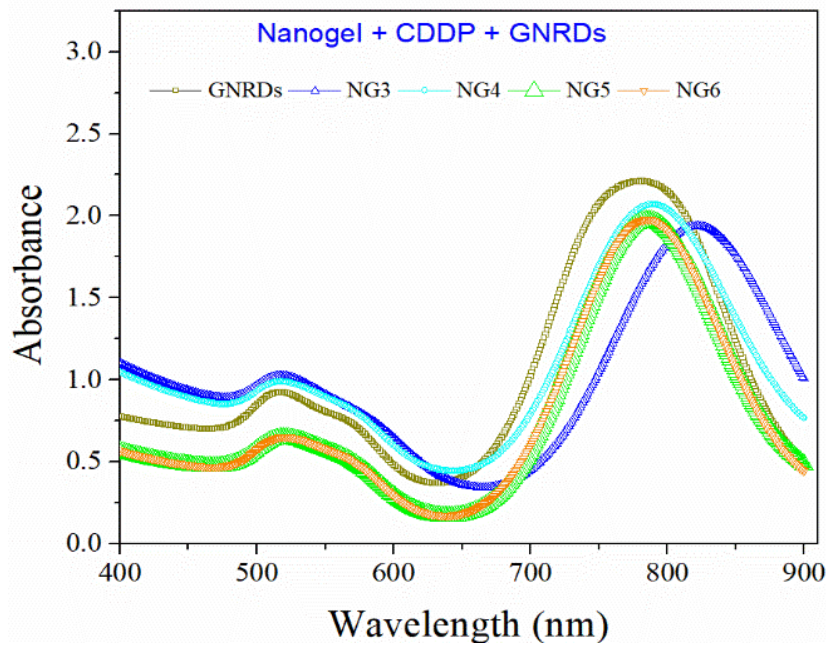

(a)

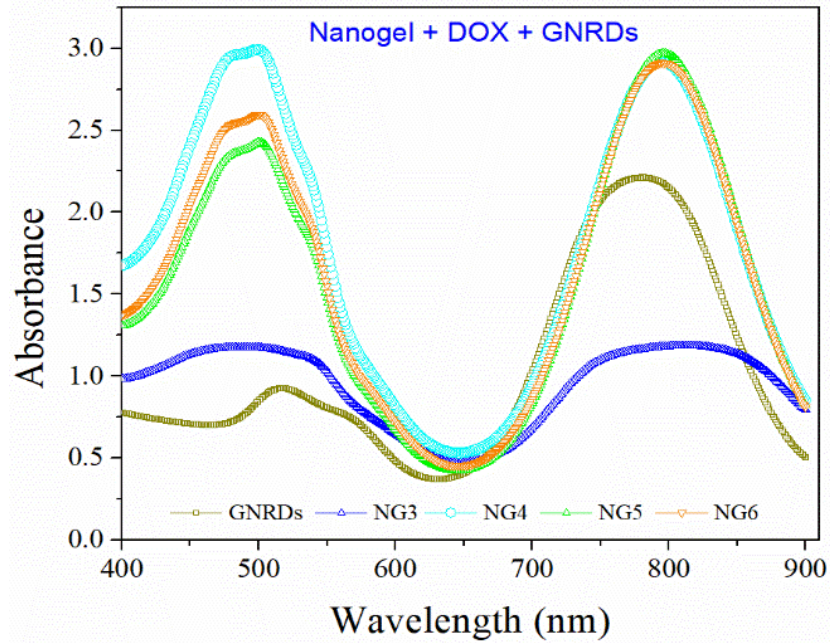

(b)

Figure 6. UV-vis spectra of GNRDs: (a) GNRDs/CDDP loaded in nanogels; and (b) GNRDs/DOX loaded in nanogels.

The encapsulation of GNRDs in nanogels was also verified via analysis of $D_{h}$ by DLS (Figure 7). As expected, the results showed an increase in size after the incorporation of the metallic nanoparticles in the polymeric networks. 


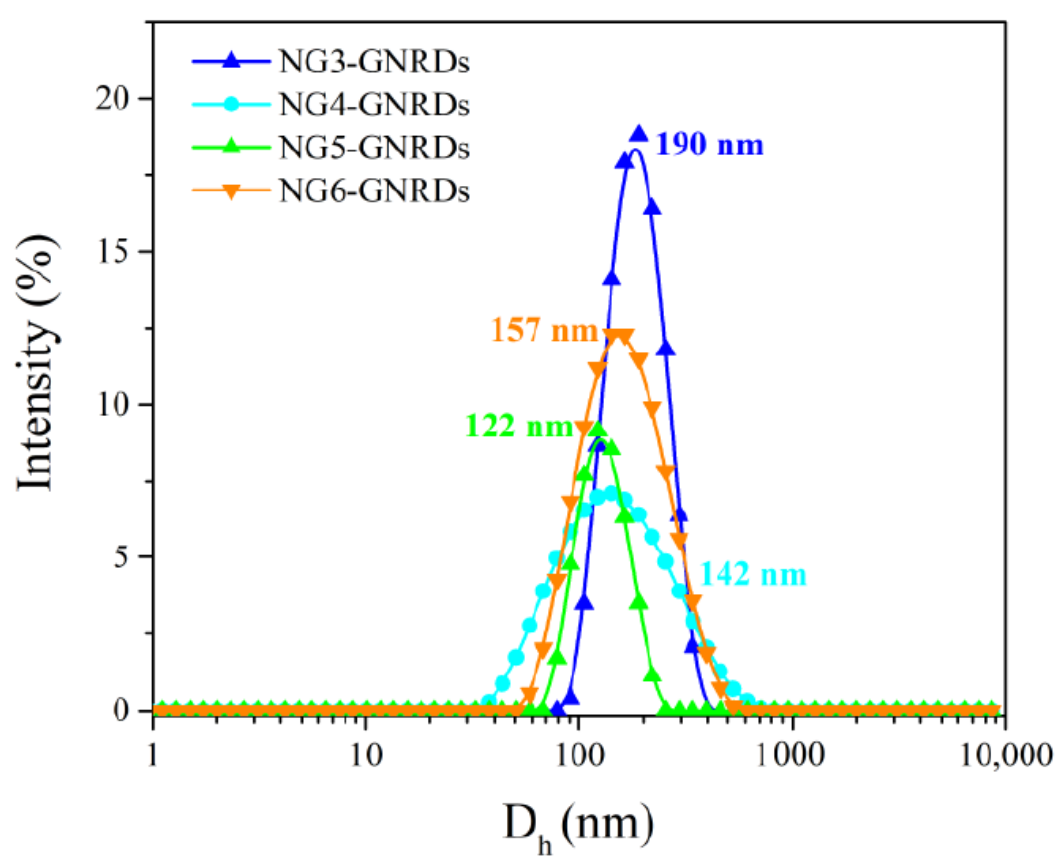

Figure 7. Size distribution by intensity of GNRDs encapsulated into PNVCL-based nanogels.

To confirm the GNRDs' photothermal effect, a $785 \mathrm{~nm}$ laser was used to irradiate the samples (Figure 8). The measurement consisted of irradiating the sample for $10 \mathrm{~min}$; during this time, the temperature data was recorded every $2 \mathrm{~s}$. The efficacy of photothermal analysis is based on the intense electromagnetic fields associated with the metal surface, which convert the energy from absorbed radiation into heat, resulting in irreparable cell damage. For these measurements, first distilled water was irradiated, showing no increase in temperature. Then, the GNRDs dispersed in distilled water were irradiated, showing a huge temperature increase of $26^{\circ} \mathrm{C}$; that is, going from 25 to $51^{\circ} \mathrm{C}$. Likewise, $1 \mathrm{mg} / \mathrm{mL}$ dispersions of nanogels loaded with GNRDs were irradiated under the same conditions.

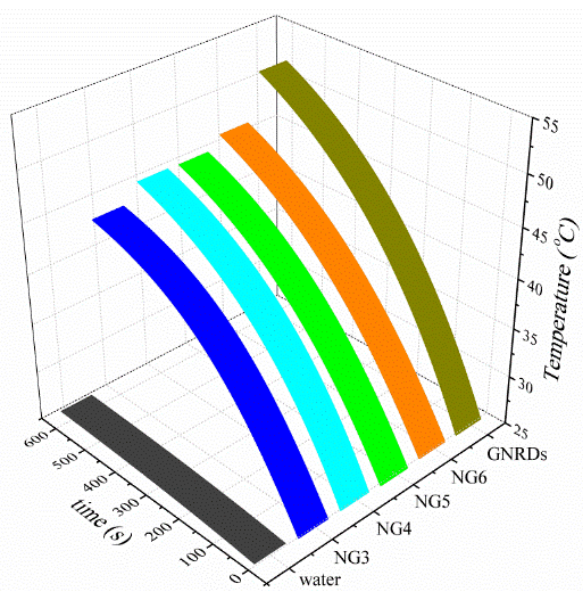

(a)

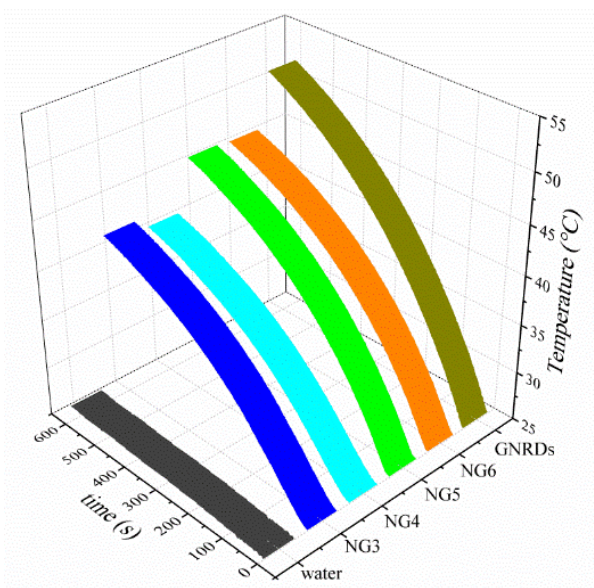

(b)

Figure 8. In situ photothermal effect monitoring of solution of: (a) GNRDs/CDDP-loaded nanogels, (b) GNRDs/DOX-loaded nanogels.

\subsection{NIR-Irradiation Triggered CDDP and DOX Release}

Release experiments of CDDP or DOX were carried out from nanogels loaded with drug and GNRDs by intermittent irradiation of samples, with a $785 \mathrm{~nm}$ laser (CNI, MDLIII-785 nm-500 mW), for 10 min every hour, for the first $6 \mathrm{~h}$ followed by a last measurement 
at $24 \mathrm{~h}$ of total incubation time; the release profiles at healthy tissue conditions $(\mathrm{pH} 7.4$ and $37^{\circ} \mathrm{C}$ ) are shown in Figure 9. It can be seen that there is a strong effect of the platform composition on the control of host molecule release, which was improved using galactofunctionalized nanogels.

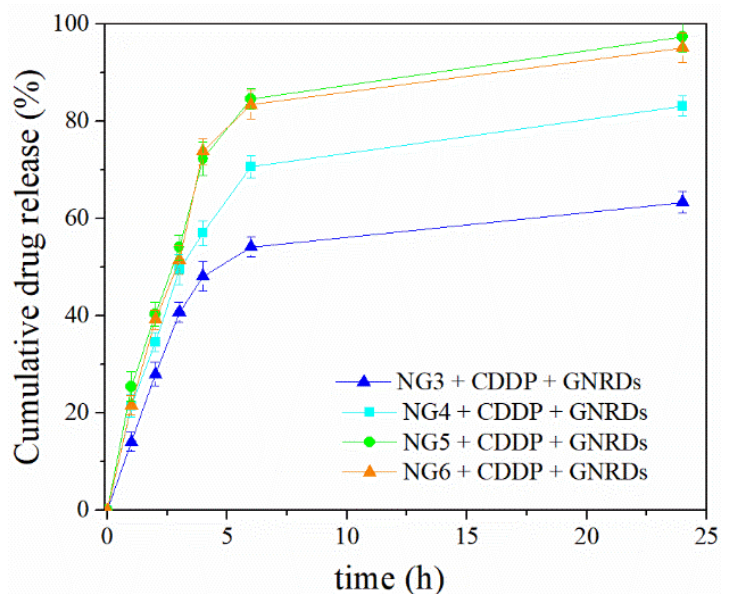

(a)

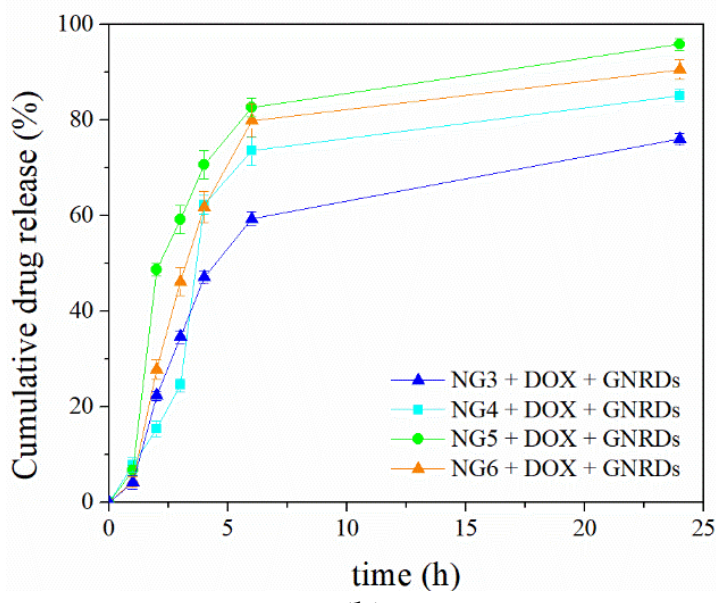

(b)

Figure 9. Cumulative drug release at $\mathrm{pH} 7.4$ and $37{ }^{\circ} \mathrm{C}$ from PNVCL:VP:PEGMA and PNVCL:GAL:PEGMA nanogels with GNRDs. The samples were irradiated with an NIR laser (500 $\mathrm{mW}$ ) for 10 min every hour until $6 \mathrm{~h}$ followed by a measurement after $24 \mathrm{~h}$ of total incubation time: (a) nanogel-CDDP-GNRDs and (b) nanogel-DOX-GNRDs.

\section{Discussion}

The aim of the present study was to evaluate the capacity of PNVCL-based nanogels to encapsulate anticancer drugs (CDDP or DOX) and metallic nanoparticles (GNRDs) for a future application in chemo- and photothermal therapy against cancer. The nanogels used for this study were characterized as previously reported [18,23], with the exception of nanogel NG6 synthesized for this study. Figure 1 shows the $D_{h}$ distributions of nanogels with different contents of VP and GAL measured in water, where narrow unimodal distributions can be seen, with $D_{h}$ between 98 and $224 \mathrm{~nm}$ and exhibiting polydispersity index (PDI) from 0.16 to 0.37 ; this demonstrates homogeneity of both types of nanogels (PNVCL:VP:PEGMA and PNVCL:GAL:PEGMA) in an aqueous medium. The content of NVCL, PEGMA, VP, and GAL in the respective nanogels was determined quantitatively by hydrogen nuclear magnetic resonance $\left({ }^{1} \mathrm{H}-\mathrm{NMR}\right)[18,23]$ and is shown in the Supplementary Information file. In general, data indicated a preferred incorporation of NVCL into nanogels with respect to the other monomers. On the other hand, the effect of temperature on the nanogel size was analyzed by DLS. Temperature-sensitive polymer networks are swollen below the $\mathrm{T}_{\mathrm{VPT}}$ and shrink above it [37]. Regarding that, the effect of the comonomer concentration (VP or GAL) on the $\mathrm{T}_{\mathrm{VPT}}$ was studied. NG1 exhibited a $\mathrm{T}_{\mathrm{VPT}}$ close to $28{ }^{\circ} \mathrm{C}$, while nanogels containing VP or GAL presented a $\mathrm{T}_{\mathrm{VPT}}$ up to $42{ }^{\circ} \mathrm{C}$. As expected, the incorporation of more hydrophilic monomers such as PEGMA or GAL in the nanogels increased the $\mathrm{T}_{\mathrm{VPT}}$. Similarly, the incorporation of a monomer with a high transition temperature, such as $N$ vinylpyrrolidone (VP), also raised the response temperature of the materials obtained [38]. The response temperatures in phosphate buffers of $\mathrm{pH} 7.4$ and 6 are similar to the values in pure water, showing differences of only one to two degrees.

The loading content of CDDP in nanogels NG1, NG2, NG3, NG4, NG5, and NG6 was between 15 and $24 \mathrm{wt} \%$, whereas the encapsulation efficiency was within the range from 60 to $85 \mathrm{wt} \%$ (Figure 2a). Likewise, the content of DOX in nanogels was determined to be between 13 and 19\%, while the encapsulation efficiency ranged from 51 to $73 \%$ (Figure 2b). In general, a slightly higher CDDP entrapment was registered, as compared with the DOX incorporation for the same type of nanogels. The encapsulation capacity using these drugs 
is attributed to the presence of hydrogen bonds and electrostatic forces between CDDP or DOX and the polymeric network, involving the amide of NVCL or VP and the ester group of PEGMA. In the case of galacto-functionalized nanogels, interactions can take place through the amide group and ester group of LAMA. Besides, the probable CDDP-polymer complexation could provide a secondary interaction between this drug and the nanogels, which also allows for controlling the burst-effect of the drug release depending on the $\mathrm{pH}$ and temperature [39]. In addition, the low molecular weight of CDDP, with respect to DOX, could favor better internalization of the drug inside the polymer network. Figure $3 a, b$ shows the CDDP release profile from PNVCL:PEGMA (NG1) and PNVCL:VP:PEGMA (NG2 and

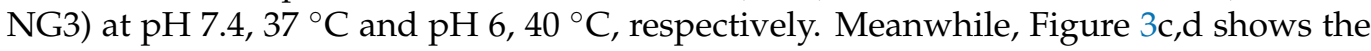
release profile of CDDP from galacto-functionalized nanogels NG4, NG5, and NG6, keeping NG1 as a reference. It can be observed that the drug release profiles depend on the nanogel composition and evidently are also influenced by the temperature and $\mathrm{pH}$ of the medium. Drug release from PNVCL:PEGMA, PNVCL:VP:PEGMA, and PNVCL:GAL:PEGMA is faster under conditions that mimic a cancer tissue as compared to healthy tissue; the CDDP release results in being slower from nanogels with higher $\mathrm{T}_{\mathrm{VPT}}$. As an example, in nanogels with VP (NG2 and NG3), the $\mathrm{T}_{\mathrm{VPT}}$ was 34 and $42{ }^{\circ} \mathrm{C}$, respectively (Table 1), and the release profiles in both cases, simulating a healthy and cancer tissue (Figure $3 a, b)$, were higher for the nanogel with lower $\mathrm{T}_{\mathrm{VPT}}$ (NG2). Similarly, in galacto-functionalized nanogels, the $\mathrm{T}_{\mathrm{VPT}}$ for NG5 and NG6 was 32 and $37.5^{\circ} \mathrm{C}$, respectively (Table 1). Drug diffusion from platforms with higher $\mathrm{T}_{\mathrm{VPT}}$ than the assay temperature could be slower because the polymer network was not shrunken. To the opposite, drug diffusion was accelerated when the assay temperature was higher than the response temperature. This highlights the control that can be achieved with these engineered thermo-sensitive materials. For instance, from the CDDP release profile at conditions that mimic a healthy tissue $\left(\mathrm{T}=37^{\circ} \mathrm{C}\right)$, the release from NG5 $\left(\mathrm{T}_{\mathrm{VPT}}=32{ }^{\circ} \mathrm{C}\right)$ was considerably higher than from NG6 $\left(\mathrm{T}_{\mathrm{VPT}}=37.5^{\circ} \mathrm{C}\right)$, showing a difference of around $20 \%$ of cumulative release of the drug. However, at conditions that mimic a cancer tissue $\left(\mathrm{T}=40^{\circ} \mathrm{C}\right)$, there were no significant differences between both systems, NG5 and NG6 reached around 90\% as maximum release at 72 h, since, in the last case, the assay temperature was higher than the response temperature of both nanogels.

Considering the systems with the lowest percentage of CDDP released under healthy cell conditions, nanogels NG3, NG4, NG5, and NG6 were selected to load and release another model drug, doxorubicin. The cumulative DOX released up to $72 \mathrm{~h}$ was around $20 \%$, resulting in small increments from the NG3 to NG6 (Figure 4a). Meanwhile, under conditions that mimic a cancer tissue, the profiles show a considerable higher release, reaching up to $70 \%$ of accumulative drug release in the case of nanogel NG5 (with lower $\mathrm{T}_{\text {VPT }}$ than the assay temperature) (Figure $4 \mathrm{~b}$ ).

The results of fitting experimental data to mathematical models are presented in Table 2 for the release of CDDP from nanogels. The most appropriate model for the adjustment was selected according to linearity $\left(r^{2}\right)$. The best fitting for CDDP release corresponds to First-order and Peppas's models. Values of $n$ obtained by Peppas's model can be used to judge the drug release mechanism and the matrix geometry [40]; if the $n$ value is lower than 0.43 , the kinetics of drug release from nanogels corresponds to a spherical matrix and a drug release mechanism controlled by Fickian diffusion. When it comes to drug release through a porous material, the value of $n$ results to be less than 0.5 due to the combination of partial diffusion mechanisms through a swollen matrix and through water-filled pores. In addition, these values denote the existence of another simultaneous diffusion process; in this case, it is attributed to the shrinkage of the networks due to the action of temperature. The same analysis was made for the DOX release profiles that mimic healthy and cancer tissue conditions (Table 3). The best-fitting models, like in CDDP, were with the first order and Peppa's models. In both cases, the release of CDDP or DOX from nanogels was controlled by Fickian diffusion. The values for the release rate constant $(k)$, for both drugs, in all models were higher for the systems that mimic cancer tissue conditions compared to those that mimic healthy tissue, which confirms the 
potential of PNVCL:PEGMA, PNVCL:VP:PEGMA, and PNVCL:GAL:PEGMA as carriers of anticancer drugs into tumor tissues.

On the other hand, gold nanostructures have been studied as therapeutic agents designed to selectively destroy cancer cells by laser-induced photothermal heating without affecting healthy cells. Moreover, nanorods may find application in biomedical imaging, drug delivery, and photothermal therapy due to the localized surface plasmon resonance (LSPR) ranging from the visible to near-infrared (NIR) region. GNRDs were synthesized by a seed-mediated growth method. Figure 5 a shows a transmittance electron microscope image; the results showed formation of gold nanorods (GNRDs) with a near-uniform length of $64 \pm 4 \mathrm{~nm}$ and diameter of $14 \pm 4 \mathrm{~nm}$ (3.75 aspect ratio). Figure $5 \mathrm{~b}$ displays the observed optical absorption of GNRDs measured by spectroscopy UV-vis. GNRDs exhibited a strong long-wavelength band due to the longitudinal oscillation of electrons at $780 \mathrm{~nm}$ and a weak short-wavelength band around $520 \mathrm{~nm}$ due to the transversal electronic oscillation. The aspect ratio of 3.75 of GNRDs supports a possible application in photothermal therapy against cancer due to their absorption overlapping with a region of minimum extinction of the human tissues. These results agree with the reports from Murphy et al. [41]. The absorption band of the GNRDs also overlaps the laser wavelength at $785 \mathrm{~nm}$ that was used in the laboratory to irradiate samples.

The synthesized GNRDs were encapsulated on selected nanogels, observing, in all cases, a shift of the longitudinal LSPR to higher wavelengths (Figure 6). In the case of GNRDs with an LSPR longitudinal band of $767 \mathrm{~nm}$, right after the purification, it was observed that the LSPR band was displaced to $780 \mathrm{~nm}$. This phenomenon is attributed to the possible agglomeration of the gold nanoparticles without CTAB and a possible increase of the local refractive index [41]. For the encapsulated GNRDs, the LSPR longitudinal bands were further displaced to values around $818 \mathrm{~nm}$ (Figure 6a) and $795 \mathrm{~nm}$ (Figure 6b) for nanogels with CDDP and DOX, respectively. The content of GNRDs in the nanogels was determined by gravimetry; the results were around $15 \%$ by weight (see Table S2 in Supplementary Information file). The increase in absorbance at $480 \mathrm{~nm}$ in Figure $6 \mathrm{~b}$ corresponds to the absorbance of DOX.

GNRD encapsulation in nanogels resulted in an increase in particle size. Figure 1 shows the sizes distribution by DLS for the empty nanogels, while Figure 7 gives the sizes of nanogels after GNRD encapsulation. The increases of $D_{h}$ were $48,13,25$, and $33 \%$ for NG3, NG4, NG5, and NG6, respectively. This increment suggested that the introduction of GNRDs into the nanogels impacted the cross-linked chains of the nucleus to be more extended and/or that a part of the metallic nanoparticles become trapped in the PEGMA shell. The results in Figure 8 show the thermal heating of the surroundings of the NG3, NG4, NG5, and NG6 nanogels in water when GNRDs were encapsulated. Figure 8a shows increases in temperature of $19,21,21$, and $22{ }^{\circ} \mathrm{C}$ for nanogels NG3, NG4, NG5, and NG6, respectively, when CDDP and GNRDs were encapsulated. Meanwhile, in nanogels with DOX/GNRDs, the increases in temperature were $17,16,21$, and $21{ }^{\circ} \mathrm{C}$ for the same materials, respectively (Figure $8 \mathrm{~b}$ ). In this sense, these materials have great potential to be used in photothermal therapy against cancer.

Studies of drug release mediated by NIR radiation were conducted. From the temperature increment studies, it was confirmed that the temperature reached, after $10 \mathrm{~min}$ of irradiation with a laser output power of $500 \mathrm{~mW}$, was high enough to allow for a thermo-sensitive response of the nanogel, while the control of pure water did not show a noticeable temperature increase. The temperature-driven contraction of the nanogel may result in squeezing out the encapsulated drug (CDDP or DOX). The nanogels possessing high $T_{\text {VPT }}$ values may minimize drug leakage during body circulation and release the drug when necessary since the incorporation of GNRDs in nanogels acts as "NIR absorbers", allowing heating and resulting in drug release by laser application without damage to the neighbor tissue without GNRDs. Figure 9 shows the characteristics of the CDDP and DOX release from nanogels with irradiation by NIR light. The samples were irradiated for a period of 10 min, every hour, with a total time of $6 \mathrm{~h}$. A faster release was observed upon 
NIR irradiation. After the first NIR exposure for $10 \mathrm{~min}$, the percentage of CDDP release increased around $10 \%$. When the samples were exposed to NIR light five times for $10 \mathrm{~min}$, the accumulated released amount of CDDP over the whole experiment process was about four-fold greater than that without laser irradiation at $\mathrm{pH} 7.4$ and $37^{\circ} \mathrm{C}$ (Figure 9a). On the other hand, DOX released after the first irradiation increased to around $5 \%$, and after five irradiations, the accumulated release increased to around 20\% compared to the release without irradiation, reaching a cumulative release from $70 \%$ to near $100 \%$ (Figure $9 \mathrm{~b}$ ). In general, it was observed that the rate of drug release was controlled by the $\mathrm{T}_{\mathrm{VPT}}$ of the nanogels, as compared to the assay temperature, and also a slightly acidic $\mathrm{pH}$ (6) accelerated the drug released due to the tertiary amine groups of the NVCL as a major component of the nanogels.

\section{Conclusions}

In summary, galacto-functionalized PNVCL-based nanogels were prepared as a multifunctional platform to combine passive and active drug delivery, NIR light-activated drug delivery, and photothermal therapy in one system simultaneously. The nanogels were obtained by surfactant-free emulsion polymerization with unimodal size distributions between 98 and $224 \mathrm{~nm}$ in hydrodynamic diameter. On the other hand, gold nanorods with a good aspect ratio were obtained. The resulting GNRDs, even after being encapsulated in the nanogels, showed surface plasmon absorbance within the NIR region, which allowed an NIR-induced temperature rise. Additionally, two model anticancer drugs (cisplatin and doxorubicin) were individually encapsulated in nanogels, obtaining loading percentages between 13 and $24 \%$ of each drug, favored by electrostatic interactions and hydrogen bonds between the drug and the polymer network. The drug release profiles indicated a low extent of release of CDDP and DOX from nanogels at conditions that mimic healthy tissue $\left(\mathrm{pH} 7.4\right.$ and $\left.37^{\circ} \mathrm{C}\right)$, and a high extent of release from the same nanogels that mimic cancer tissue ( $\mathrm{pH} 6$ and $40^{\circ} \mathrm{C}$ ), which was confirmed from the release rate constant $(k)$ obtained by fitting experimental data to mathematical models. Peppas model suggested a Fickian diffusion of CDDP and DOX through spherical nanogels. In addition, the dual encapsulation of drug-GNRDs was performed, yielding Nanogel-CDDP-GNRDs and Nanogel-DOX-GNRDs and obtaining quite significant increases in the accumulated release in the systems with irradiation. The double encapsulation capacity of nanogels (drug + GNRDs) and the in vitro release profiles demonstrated the potential of PNVCL-based nanogels as drug delivery systems for chemo- and photothermal therapy against cancer.

Supplementary Materials: The following supporting information can be downloaded at: https: //www.mdpi.com/article/10.3390/pharmaceutics14030560/s1, Figure S1: Berry plot by SLS of nanogel NG2, Table S1. Characterization of nanogels, Table S2. GNRDs loading percentage in nanogels, Figure S2. Hydrodynamic diameter of nanogel NG1 as function of temperature in PBS at pH 7.4 and 6, Figure S3. Hydrodynamic diameter of nanogel NG2 as function of temperature in PBS at pH 7.4 and 6, Figure S4. Hydrodynamic diameter of nanogel NG3 as function of temperature in PBS at pH 7.4 and 6, Figure S5. Hydrodynamic diameter of nanogel NG4 as function of temperature in PBS at $\mathrm{pH} 7.4$ and 6, Figure S6. Hydrodynamic diameter of nanogel NG5 as function of temperature in PBS at pH 7.4 and 6, Figure S7. Hydrodynamic diameter of nanogel NG6 as function of temperature in water and in PBS at pH 7.4 and 6, Figure S8. 1H-NMR spectrum of nanogel NG6, Figure S9. Thermogram by DSC of nanogel NG6, Figure S10. Thermogram by TGA of nanogel NG6.

Author Contributions: Investigation, methodology, visualization, writing-original draft, M.A.G.-A.; formal analysis, validation, and review and editing, J.L.-R.; funding acquisition, project administration, validation, and review and editing, E.R.M.; conceptualization, formal analysis, funding acquisition, project administration, supervision, and review and editing, A.L.-C. All authors have read and agreed to the published version of the manuscript.

Funding: This research was funded by the National Council of Science and Technology of Mexico (CONACyT), grant number 2016-CB-285419.

Institutional Review Board Statement: Not applicable. 
Informed Consent Statement: Not applicable.

Data Availability Statement: Not applicable.

Acknowledgments: The authors thank the following persons for supporting experiments: Leidy Paola Quiroga-Sánchez (CICESE) for laser irradiation; Valentin Miranda Salazar (IT-Tijuana) for NMR measurements; and Gabriela Guzmán (LNMA from CICESE) for TEM micrographies.

Conflicts of Interest: The authors declare no conflict of interest.

\section{References}

1. Rahdar, A.; Sayyadi, K.; Sayyadi, J.; Yaghobi, Z. Nanogels: A versatile nano-carrier platform for drug delivery systems: A mini review. Nanomed. Res. J. 2019, 4, 1-9.

2. Jha, A.; Rama, A.; Ladani, B.; Verma, N.; Kannan, S.; Naha, A. Temperature and pH-responsive nanogels as intelligent drug delivery systems: A comprehensive review. J. Appl. Pharm. Sci. 2021, 11, 1-16. [CrossRef]

3. Ahmed, S.; Alhareth, K.; Mignet, N. Advancement in nanogel formulations provides controlled drug release. Int. J. Pharm. 2020, 584, 119435. [CrossRef] [PubMed]

4. Salahpour-Anarjan, F. Active targeting drug delivery nanocarriers: Ligands. Nano-Struct. Nano-Objects 2019, 19, 100370. [CrossRef]

5. Montane, X.; Bajek, A.; Roszkowski, K.; Montornes, J.M.; Giamberini, M.; Roszkowski, S.; Kowalczyk, O.; Garcia-Valls, R.; Tylkowski, B. Encapsulation for cancer therapy. Molecules 2020, 25, 1605. [CrossRef] [PubMed]

6. Wang, S.; Zhang, Q.; Yang, P.; Yu, X.; Huang, L.; Shen, S.; Cai, S. Manganese oxide-coated carbon nanotubes as dual-modality lymph mapping agents for photothermal therapy of tumor metastasis. ACS Appl. Mater. Interfaces 2016, 8, 3736-3743. [CrossRef]

7. Ali, M.R.; Ali, H.R.; Rankin, C.R.; El-Sayed, M.A. Targeting heat shock protein 70 using gold nanorods enhances cancer cell apoptosis in low dose plasmonic phothermal therapy. Biomaterials 2016, 102, 1-8. [CrossRef]

8. Zhang, L.; Chen, Y.; Li, Z.; Li, L.; Saint-Cricq, P.; Li, C.; Lin, J.; Wang, C.; Su, Z.; Zink, J.I. Tailored synthesis of octopus-type janus nanoparticles for synergistic actively-targeted and chemo-phothermal therapy. Angew. Chem. 2016, 128, 2158-2161. [CrossRef]

9. Chen, Y.; Su, Y.; Hu, S.; Chen, S. Functionalized graphene nanocomposites for enhancing photothermal therapy in tumor treatment. Adv. Drug Deliv. Rev. 2016, 105, 190-204. [CrossRef]

10. Gao, J.; Wu, C.; Deng, D.; Wu, P.; Cai, C. Direct synthesis of water-soluble aptamer-Ag2S quantum dots at ambient temperature for specific imaging and photothermal therapy of cancer. Adv. Healthc. Mater. 2016, 5, 2437-2449. [CrossRef] [PubMed]

11. Guo, M.; Xiang, H.; Wang, Y.; Zhang, Q.; An, L.; Yang, S.; Ma, Y.; Wang, Y.; Liu, J. Ruthenium nitrosyl functionalized graphene quantum dots as an efficient nanoplatform for NIR-light-controlled and mitochondria-targeted delivery of nitric oxide combined with photothermal therapy. Chem. Commun. 2017, 53, 3253-3256. [CrossRef]

12. Chen, W.H.; Xu, X.D.; Jia, H.Z.; Lei, Q.; Luo, G.F.; Cheng, S.X.; Zhuo, R.X.; Zhang, X.Z. Therapeutic nanomedicine based on dual-intelligent functionalized gold nanoparticles for cancer imaging and therapy in vivo. Biomaterials 2013, 34, 8798-8807. [CrossRef] [PubMed]

13. Yang, J.; Yao, M.H.; Jin, R.M.; Zhao, D.H.; Zhao, Y.D.; Liu, B. Polypeptide-engineered hydrogel coated gold nanorods for targeted drug delivery and chemo-photothermal therapy. ACS Biomater. Sci. Eng. 2017, 3, 2391-2398. [CrossRef] [PubMed]

14. Penninckx, S.; Heuskin, A.C.; Michiels, C.; Lucas, S. Gold nanoparticles as a potent radiosensitizer: A transdisciplinary approach from physics to patient. Cancers 2020, 12, 2021. [CrossRef] [PubMed]

15. Tremi, I.; Spyratou, E.; Souli, M.; Efstathopoulos, E.P.; Makropoulou, M.; Georgakilas, A.G.; Sihver, L. Requirements for designing an effective metallic nanoparticle (NP)-boosted radiation therapy (RT). Cancers 2021, 13, 3185. [CrossRef] [PubMed]

16. Cortez-Lemus, N.A.; Licea-Claverie, A. Poly( $N$-vinylcaprolactam), a comprehensive review on a thermoresponsive polymer becoming popular. Prog. Polym. Sci. 2016, 53, 1-51. [CrossRef]

17. Macchione, M.A.; Guerrero-Beltran, C.; Rosso, A.P.; Euti, E.M.; Martinelli, M.; Strumia, M.C.; Muñoz-Fernandez, M.A. Poly(Nvinylcaprolactam) nanogels with antiviral behavior against HIV-1 infection. Sci. Rep. 2019, 9, 5732. [CrossRef] [PubMed]

18. Gonzalez-Ayon, M.A.; Sañudo-Barajas, J.A.; Picos-Corrales, L.A.; Licea-Claverie, A. PNVCL-PEGMA nanohydrogels with tailored transition temperature for controlled delivery of 5-fluorouracil. J. Polym. Sci. A Polym. Chem. 2015, 53, 2662-2672. [CrossRef]

19. Rejinold, N.S.; Baby, T.; Chennazhi, K.P.; Jayakumar, R. Multi drug loaded thermo-responsive fibrinogen-graft-poly(Nvinylcaprolactam) nanogels for breast cancer drug delivery. J. Biomed. Nanotechnol. 2015, 11, 392-402. [CrossRef] [PubMed]

20. Wang, Y.; Nie, Y.; Chang, B.; Sun, Y.; Yang, W. Poly(vinylcaprolactam)-based biodegradable multiresponsive microgels for drug delivery. Biomacromolecules 2013, 14, 3034-3046. [CrossRef] [PubMed]

21. Rao, K.M.; Mallikarjuna, B.; Rao, K.S.V.K.; Siraj, S.; Rao, K.C.; Subha, M.C.S. Novel thermo/pH sensitive nanogels composed from poly( $N$-vinylcaprolactam) for controlled release of an anticancer drug. Colloids Surf. B 2013, 102, 891-897.

22. Lou, S.; Gao, S.; Wang, W.; Zhang, M.; Wang, C.; Li, C.; Kong, D.; Zhao, Q. Galactose-functionalized multiresponsive nanogels for hepatoma-targeted drug delivery. Nanoscale 2015, 7, 3137-3146. [CrossRef]

23. González-Ayón, M.A.; Licea-Claverie, A.; Sañudo-Barajas, J.A. Different strategies for the preparation of galactose-functionalized thermos-responsive nanogels with potential as smart drug delivery systems. Polymers 2020, 12, 2150. [CrossRef]

24. Paasonen, L.; Laaksonen, T.; Johans, C.; Yliperttula, M.; Kontturi, K.; Urtti, A. Gold nanoparticles enable selective light-induced contents release from liposomes. J. Control Release 2007, 122, 86-93. [CrossRef] [PubMed] 
25. Collins, C.B.; McCoy, R.S.; Ackerson, B.J.; Collins, G.J.; Ackerson, C.J. Radiofrequency heating pathways for gold nanoparticles. Nanoscale 2014, 6, 8459-8472. [CrossRef]

26. Pantano, P.; Harrison, C.D.; Poulose, J.; Urrabazo, D.; Norman, T.Q.; Braun, E.I.; Draper, R.K.; Overzet, L.J. Factors affecting the 13.56-MHz radio-frequency-mediated heating of gold nanoparticles. Appl. Spectrosc. Rev. 2017, 52, 821-836. [CrossRef]

27. Siirila, J.; Karesoja, M.; Pulkkinen, P.; Malho, J.M.; Tenhu, H. Soft poly(N-vinylcaprolactam) nanogels Surface-decorated with AuNPs. Response to temperature, light and RF-field. Eur. Polym. J. 2019, 115, 59-69. [CrossRef]

28. Mukherjee, M.B.; Mullick, R.; Reddy, B.U.; Das, S.; Raichur, A.M. Galactose functionalized mesoporous silica nanoparticles as delivery vehicle in the treatment of hepatitis C infection. ACS Appl. Mater. 2020, 3, 7598-7610. [CrossRef] [PubMed]

29. González-Ayón, M.A.; Licea-Claverie, A.; Valdez-Torres, J.B.; Picos-Corrales, L.A.; Velez-de la Rocha, R.; Contreras-Esquivel, J.C.; Labavitch, J.M.; Sañudo-Barajas, J.A. Enzyme-catalyzed production of potato galacto-oligosaccharides and its optimization by response Surface methodology. Materials 2019, 12, 1465. [CrossRef]

30. Liu, J.; Detrembleur, C.; De Pauw-Gillet, M.C.; Mornet, S.; Duget, E.; Jerome, C. Gold nanorods coated with a thermo-responsive poly(ethylene glycol)-b-poly( $N$-vinylcaprolactam) corona as drug delivery systems for remotely near infrared release. Polym. Chem. 2014, 5, 799-813. [CrossRef]

31. DiazDuarte-Rodriguez, M.; Cortez-Lemus, N.A.; Licea-Claverie, A.; Licea-Rodriguez, J.; Mendez, E.R. Dual responsive polymersomes for gold nanorod and doxorrubicin encapsulation: Nanomaterials with potential use as Smart drug delivery systems. Polymers 2019, 11, 939. [CrossRef] [PubMed]

32. Dasari, S.; Tchounwoum, P.B. Cisplatin in cancer therapy: Molecular mechanisms of action. Eur. J. Pharmacol. 2014, 740, 364-378. [CrossRef] [PubMed]

33. Yang, F.; Teves, S.S.; Kemp, C.J.; Henikoff, S. Doxorubicin, DNA torsion, and chromatin dynamics. Biochim. Biophys. Acta 2014, 1845, 84-89. [CrossRef] [PubMed]

34. Gonzalez-Urias, A.; Zapata-Gonzalez, I.; Licea-Claverie, A.; Licea-Navarro, A.F.; Bernaldez-Sarabia, J.; Cervantes-Luevano, K. Cationic versus anionic core-shell nanogels for transport of cisplatin to lung cancer cells. Colloids Surf. B 2019, 182, 110365. [CrossRef]

35. Gallo, E.; Diaferia, C.; Smaldone, G.; Morelli, G.; Accardo, A. Peptide-based hydrogels and nanogels for delivery of doxorubicin. Int. J. Nanomed. 2021, 16, 1617-1630. [CrossRef] [PubMed]

36. Chen, Y.C.; Liao, L.C.; Lu, P.L.; Lo, C.L.; Tsai, H.C.; Huang, C.Y.; Wei, K.C.; Yen, T.C.; Hsiue, G.H. The accumulation of dual pH and temperature responsive micelles in tumors. Biomaterials 2012, 33, 4576-4588. [CrossRef] [PubMed]

37. Judah, H.L.; Liu, P.; Zarbakhsh, A.; Resmini, M. Influence of buffers, ionic strength, and pH on the volume phase transition behavior of acrylamide-based nanogels. Polymers 2020, 12, 2590. [CrossRef]

38. Zhang, X.; Yang, Z.; Xie, D.; Liu, D.; Chen, Z.; Li, K.; Li, Z.; Tichnell, B.; Liu, Z. Design and synthesis study of the thermos-sensitive poly (N-vinylpyrrolidone-b-N,N-diethylacrylamide). Des. Monomers Polym. 2018, 21, 43-54. [CrossRef]

39. Yan, X.; Gemeinhart, R.A. Cisplatin delivery from poly(acrylic acid-co-methyl methacrylate) microparticles. J. Control Release 2005, 106, 198-208. [CrossRef] [PubMed]

40. Dibic, S.N.; Filipovic, J.M.; Tomic, S.L. Synthesis and characterization of poly(2-hydroxyethyl methacrylate/itaconic acid/poly(ethylene glycol) dimethacrylate) hydrogels. Chem. Eng. J. 2012, 179, 372-380. [CrossRef]

41. Burrows, N.D.; Lin, W.; Hinman, J.G.; Dennison, J.M.; Vartanian, A.M.; Abadeer, N.S.; Grzincic, E.M.; Jacob, L.M.; Murphy, C.J. Surface chemistry of gold nanorods. Langmuir 2016, 32, 9905-9921. [CrossRef] [PubMed] 